\title{
Conduta no tratamento do divertículo de uretra feminina
}

\section{Treatment approach to female urethral diverticulum}

\author{
Nelson Alfredo Smith ${ }^{1}$
}

\section{R E S U M O}

\begin{abstract}
Os divertículos de uretra feminina são incomuns e são mais freqüentes entre a terceira e a quinta décadas de vida. Geralmente é diagnosticado tardiamente. A maioria dos divertículos de uretra está relacionada à infecções recorrentes das glândulas periuretrais ou ao traumatismo uretral. . A uretrocistografia e a ressonância magnética são os métodos de imagem de maior valor no diagnóstico desta doença. O tratamento de eleição e a ressecção do divertículo.
\end{abstract}

Descritores: Diagnóstico. Doença. Divertículo. Uretra. Saúde da mulher.

INTRODUÇÃO

O divertículo da uretra feminina, congênito ou adquirido é uma doença pouco frequente, e sua incidência varia de 0,6 a $6 \%$ da população feminina ${ }^{1-4}$. Apresenta-se, geralmente, entre a terceira e quinta décadas da vida, embora tenha sido encontrado em recém-nascidas e muIheres jovens ${ }^{3-6}$. Ocorre predominantemente nos dois terços distais da uretra ${ }^{2,3}$, algumas séries indicam um acometimento maior das mulheres negras ${ }^{2,4}$. Em geral o diagnóstico é feito tardiamente, após vários atendimentos médicos $4,5,7-11$

Embora haja um aumento de incidência de divertículos de uretra feminina acredita-se que realmente este aumento seja devido a uma maior consciência da existência desta doença associada ao progresso dos atuais métodos de imagem $3,5,8,12$.

A teoria mais aceita para explicar a formação destes diverticulos preconiza que eles sejam provenientes de lesões adquiridas, originadas das glândulas periuretrais de Skene, que sofrem uma dilatação cística e, após terem seu conteúdo infectado, abscedam. Este abscesso abre-se para a luz uretral com a conseqüente formação do divertículo $2,7,9,12$.

Foram descritas distensões localizadas de uretra como alterações anatômicas que podem simular um divertículo de uretra ${ }^{7}$. Alguns autores ao demonstrar que os aspectos histopatológicos do divertículo de uretra são semelhantes aos observados nos cistos parauretrais sugerem que estas doenças não devam ser consideradas distintas $^{5,12}$.

A escassez de relatos, na literatura nacional, sobre o divertículo de uretra feminina nos estimulou a elaborar estes comentários técnicos sobre o tratamento cirúrgico desta doença.

\section{QUADRO CLÍNICO}

Em muitas pacientes os divertículos são assintomáticos,.e podem estar associados à infecções urinárias de repetição ou à manifestações locais de inflamação.

Na maioria das vezes podem ser encontrados vários sinais e sintomas: dor na uretra, disúria, polaciúria, urgência urinária, hematúria, uretrorragia; tornando a tríade sintomática clássica composta por disuria, dispareunia e gotejamento terminal de urina, infreqüente $e^{2,6,8,9}$. Ao exame físico os divertículos se apresentam como tumorações localizadas na porção súpero-distal da vagina, na linha média (Figura 1), e a consistência destas tumorações depende do conteúdo do divertículo que pode ser formado

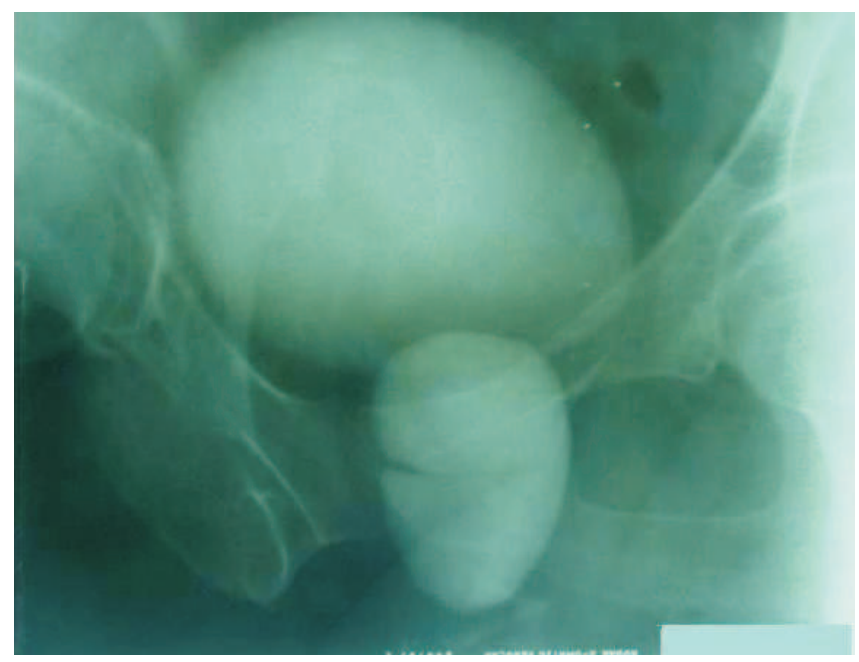

Figura 1 - Uretrocistografia miccional mostrando formação ovoide contrastada, abaixo da bexiga, compatível com volumoso divertículo de uretra.

1. Professor Associado do Departamento de Cirurgia da Faculdade de Medicina da UFRJ. 
por líquido, cálculo ou tumor ${ }^{8}$. Quando o divertículo contiver material infectado, a expressão da tumoração dará saída à material purulento pelo meato uretral 2,10.

A presença de cálculos no interior do divertículo é infreqüente e ocorre em 5,7 a $10 \%$ dos casos $^{13}$. A presença de neoplasias em diverticulos uretrais é rara . Embora o carcinoma que mais acometa a uretra feminina seja o escamoso, nos divertículos predominam os adenocarcinomas, com cerca de $70 \%$ de prevalência sobre todos os carcinomas $2,3,4,10,13,14$. A lítíase e a neoplasia podem coexistir no mesmo divertículo ${ }^{13}$. Tem sido sugerido que os mesmos fatores que levam à formação de cálculos seriam responsáveis pela gênese das lesões neoplásicas nos diverticulos ${ }^{15}$. Excepcionalmente os divertículos se apresentam com obstrução do colo vesical ou até mesmo com retenção aguda de urina $a^{2,4,6,16,17}$.

Como disse Moore ${ }^{1}$ o diagnóstico do divertículo de uretra feminina está diretamente relacionado à vontade do cirurgião em descobri-lo.

\section{Emprego dos métodos de imagem}

Historicamente os métodos de imagem mais utilizados para o diagnostico dos divertículos de uretra têm sido a uretrocistografia miccional e a uretrocistografia de pressão positiva com cateter de duplo balão (Figura 2), A uretrocistografia miccional identifica os divertículos em 90\% dos casos como uma coleção de contraste redonda ou oval logo abaixo da sínfise pubiana ${ }^{15}$. São exames invasivos, pois necessitam de cateterismo vesical e podem provocar infecção urinária ${ }^{18}$. Os cálculos ou tumores que ocupam o interior dos divertículos podem ser vistos como imagem de falha de enchimento nos exames radiológicos contrastados e os divertículos do 1/3 proximal da uretra, que são menos freqüentes, quando se extendem cranialmente podem elevar a base da bexiga, provocando uma imagem semelhante a uma próstata aumentada de volume ${ }^{15}$.

Na última década a ultrassonografia tornou-se um exame de grande valor para auxiliar no diagnóstico do divertículo de uretra com a vantagem de não utilizar radiação ionizante, ser pouco dispendioso e proporcionar imagens em diferentes orientações ${ }^{19}$.

A Ressonância Magnética (RM) tem contribuído muito para o diagnóstico do divertículo de uretra, identificando sua configuração anatômica precisa, sua posição, extensão e relação com a uretra e evidenciando as neoplasias existentes no interior do divertículo. ${ }^{10,20}$, com a vantagem de não ser método invasivo $0^{5,8,10,18,20-23}$. De acordo com a imagem da RM os divertículos de uretra podem ser classificados em 3 tipos: divertículos simples, divertículos em forma de $\mathrm{U}$ (Figura 3 ) e divertículos circunferenciais ou em ferradura ${ }^{5}$. Atualmente a uretrocistografia miccional e a RM são considerados os métodos diagnósticos de maior valor ${ }^{3,5,8}$, havendo uma crescente evidência de que a RM é o exame radiológico com maior sensibilidade para o diagnóstico do divertículo de uretra, identificando a lesão mesmo quando a uretrocistografia miccional é normal ${ }^{24}$

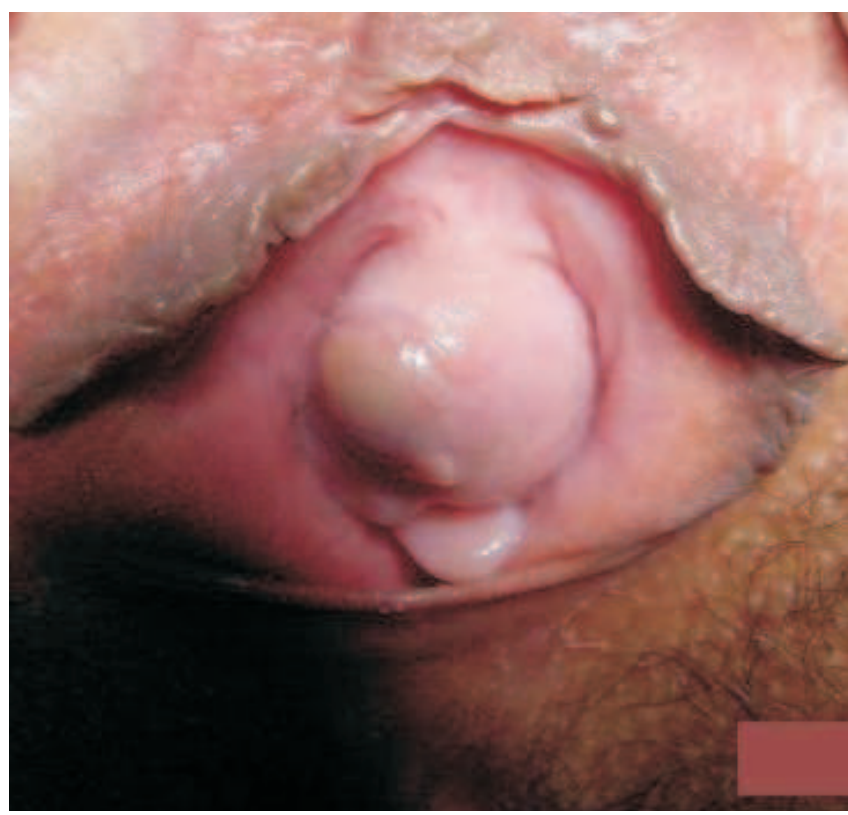

Figura 2 - $\quad$ Aspecto típico do diverticulo uretral.

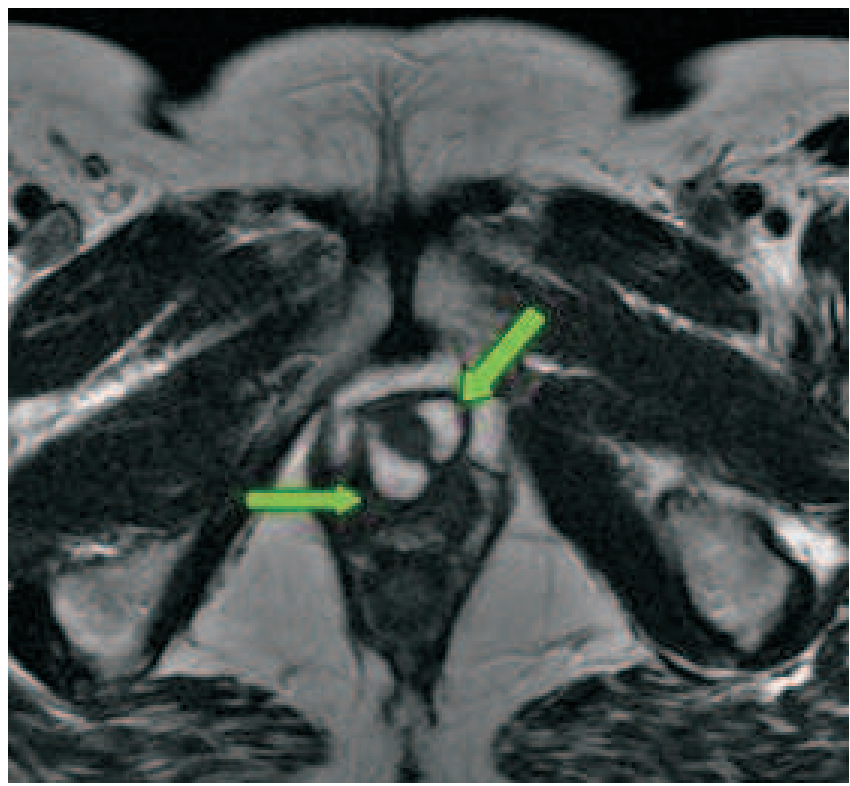

Figura 3 - $\quad$ RM axial T2 mostra diverticulo uretral com forma de U; cortesia do Dr. Leonardo Kayat Bittencourt.

A RM é de grande valia para o planejamento da cirurgia, particularmente nos divertículos circunferenciais 5,8,22

Os pacientes com divertículo de uretra que apresentam incontinência urinaria de esforço também deverão ser submetidos aos exames de videourodinâmica ${ }^{8}$. A uretrocistoscopia deve ser indicada na tentativa de identificação do óstio uretral do divertículo e para afastar outras doenças vesicais ${ }^{8,16}$

\section{Tratamento: aspectos técnicos}

O divertículo deve ser completamente excisado após cuidadosa dissecção. O fechamento deve ser feito 
em três planos interessando orifício uretral, fáscia periuretral e parede vaginal $\left.\right|^{5,6,8,20,24}$. O tratamento definitivo do divertículo de uretra é cirúrgico e o acesso é feito por via transvaginal8,16.

Os divertículos pequenos e próximos ao meato uretral podem ser tratados com uma simples marsupialização6,17. Os divertículos grandes, múltiplos ou circunferenciais tornam a operação complexa, explicando, desta forma, o alto índice de reoperações necessárias para a resolução total dos sintomas 5,17,24. Estes divertículos necessitam de dissecção extensa da uretra em toda sua circunferência resultando em perda de segmento uretral e um grande espaço morto ${ }^{22}$. Nestes casos aplicam-se retalhos como o músculo gracilis, retalho de Martius, grande omento ou enxerto com derme de porco ${ }^{11}$. Alguns autores utilizam o enxerto labial de Martius como uma tentativa de diminuir a possibilidade de formação de fistula uretro-vaginal ${ }^{8,16}$.

Quando coexistem divertículo uretral e incontinência urinaria de esforço, o tratamento simultâneo é controverso $0^{5,6,8,16,17}$, pois ocorrerá a modificação anatômica da uretra causada pela operação para corrigir a incontinência urinária e esta alteração anatômica dificultará a exposição da uretra numa possível reintervenção ${ }^{17}$. É importante assinalar que se a opção for pelo tratamento simultâneo, os materiais sintéticos utilizados para a correção da incontinência urinária devem ser evitados 12,16,17,22

Nos casos de divertículos contendo tumor o tratamento deverá ser extensa, podendo ser necessário o emprego da uretrocistectomia radical com derivação urinaria e também de radioterapia. 2,3,14.

A técnica utilizada em nossa paciente, portadora de um diverticulo grande e do tipo simples, foi a diverticulectomia por via vaginal preconizada por Moore1, onde o balão do cateter de Foley, sem o bulbo, é introduzido e insuflado no interior do divertículo para facilitar sua dissecção (Figura 4). A paciente evoluiu bem, sem intercorrências, estando assintomática após um ano de seguimento pós-operatorio e sem recidiva do divertículo.

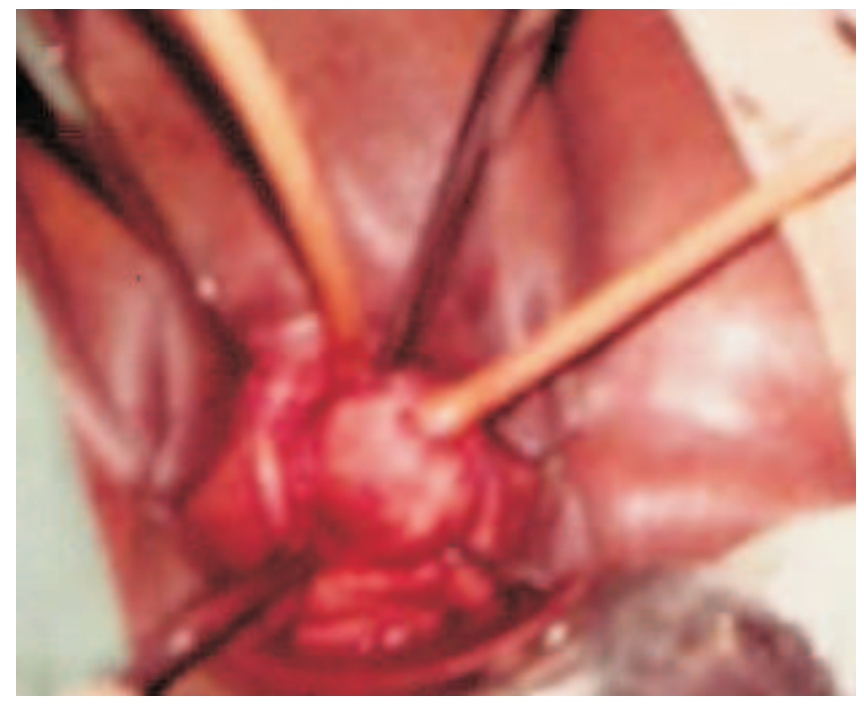

Figura 4 - $\quad$ Aspecto cirúrgico mostrando o balão do cateter de Foley insuflado dentro do diverticulo (técnica de Moore).

As principais complicações pós operatórias são: a recidiva do divertículo e a fistula uretro-vaginal. Os fatores de risco para recidiva são divertículos circunferenciais e reoperações ${ }^{8}$ e os sintomas residuais acometem mais as pacientes submetidas a repetidas operações do que aquelas submetidas às ressecções primárias extensas ${ }^{17}$. A incontinência urinaria de esforço e, também, as lesões vesicais podem ocorrer, porém são menos frequentes ${ }^{5,17}$.

\section{Agradecimentos}

Sra. Maria de Fátima Pinto, Secretária Sênior do Departamento de Ortopedia da Fac Med UFRJ, pela excelência no preparo das referências bibliográficas.

Dr Leonardo Kayat Bittencourt, Radiologista Especialista em Ressonância Magnética do Abdômen e Pelve, pela cortesia em ceder a foto da Ressonância Magnética.

\section{A $B$ B $S$ T $R$ R A C $C$}

Female urethral diverticula are uncommon and are more frequent between the third and fifth decades of life. They are usually diagnosed late. Most urethral diverticula are related to recurrent infections of the periurethral glands or urethral trauma. Cystourethrography and magnetic resonance imaging are the most valuable diagnostic methods. The treatment of choice is thte resection of the diverticulum.

Key words: Diagnosis. Disease. Diverticulum, Urethra. Women's health.

\section{REFERÊNCIAS}

1. Moore TD. Diverticulum of female urethra; an improved technique of surgical excision. J Urol 1952;68(3):611-6.

2. Seballos RM, Rich RR. Clear cell adenocarcinoma arising from a urethral diverticulum. J Urol 1995;153(6):1914-5.

3. Thomas AA, Rackley RR, Lee U, Goldman HB, Vasavada SP, Hansel DE. Urethral diverticula in 90 female patients: a study with emphasis on neoplastic alterations. J Urol 2008;180(6):2463-7.
4. Patel AK, Chapple CR. Female urethral diverticula. Curr Opin Urol 2006;16(4):248-54.

5. Han DH, Jeong YS, Choo MS, Lee KS. Outcomes of surgery of female urethral diverticula classified using magnetic resonance imaging. Eur Urol 2007;51(6):1664-70.

6. Ganabathi K, Leach GE, Zimmern PE, Dmochowski R. Experience with the management of urethral diverticulum in 63 women. J Urol 1994;152(5 Pt 1):1445-52. 
7. Stewart M, Bretland PM, Stidolph NE. Urethral diverticula in the adult female. Br J Urol 1981;53(4):353-9.

8. Ockrim JL, Allen DJ, Shah PJ, Greenwell TJ. A tertiary experience of urethral diverticulectomy: diagnosis, imaging and surgical outcomes. BJU Int 2009;103(11): 1550-4.

9. Rufford J, Cardozo L. Urethral diverticula: a diagnostic dilemma. BJU Int 2004; 94(7):1044-7.

10. Kim B, Hricak $H$, Tanagho EA. Diagnosis of urethral diverticula in women: value of $M R$ imaging. AJR Am J Roentgenol 1993;161(4):809-15.

11. Clyne OJ, Flood HD. Giant urethral diverticulum: a novel approach to repair. J Urol 2002;167(4):1796.

12. Tsivian M, Tsivian A, Shreiber L, Sidi AA, Koren R. Female urethral diverticulum: a pathological insight. Int Urogynecol J Pelvic Floor Dysfunct 2009;20(8):957-60.

13. Tines SC, Bigongiari LR, Weigel JW. Carcinoma in diverticulum of the female urethra. AJR Am J Roentgenol 1982;138(3):582-5.

14. Cocco AE, MacLennan GT. Unusual female suburethral mass lesions. J Urol 2005; 174(3): 1106.

15. Amis Jr ES, Newhouse JH. Essentials of uroradiology. Boston: Little Brown; 1991

16. Romanzi LJ, Groutz A, Blaivas JG. Urethral diverticulum in women: diverse presentations resulting in diagnostic delay and mismanagement. J Urol 2000;164(2):428-33.

17. Ljungqvist $L$, Peeker R, Fall M. Female urethral diverticulum: 26year followup of a large series. J Urol 2007;177(1):219-24; discussion 224.

18. Blander DS, Rovner ES, Schnall MD, Ramchandani P, Banner MP, Broderick GA, et al. Endoluminal magnetic resonance imaging in the evaluation of urethral diverticula in women. Urology 2001;57(4):660-5

19. Siegel $C L$, Middleton WD, Teefey SA, Wainstein MA, McDougall EM, Klutke CG. Sonography of the female urethra. AJR Am J Roentgenol 1998;170(5):1269-74.
20. Foster RT, Amundsen CL, Webster GD. The utility of magnetic resonance imaging for diagnosis and surgical planning before transvaginal periurethral diverticulectomy in women. Int Urogynecol J Pelvic Floor Dysfunct 2007;18(3):315-9.

21. Bennett GL, Hecht EM, Tanpitukpongse TP, Babb JS, Taouli B, Wong $S$, et al. MRI of the urethra in women with lower urinary tract symptoms: spectrum of findings at static and dynamic imaging. AJR Am J Roentgenol 2009;193(6):1708-15.

22. Rovner ES, Wein AJ. Diagnosis and reconstruction of the dorsal or circumferential urethral diverticulum. J Urol 2003;170(1):82-6; discussion 86.

23. Neitlich JD, Foster HE Jr, Glickman MG, Smith RC. Detection of urethral diverticula in women: comparison of a high resolution fast spin echo technique with double balloon urethrography. Urol 1998;159(2):408-10.

24. Wright JL, Miller JL. Female urethral diverticulum: diverse presentation and surgical results. J Pelvic Med Surg 2005;11(4):191-4.

Recebido em 08/11/2010

Aceito para publicação em 08/01/2011

Conflito de interesse: nenhum

Fonte de financiamento: nenhum

\section{Como citar este artigo:}

Smith NA. Conduta no tratamento do divertículo de uretra feminina. Rev Col Bras Cir. [periódico na Internet] 2011; 38(6). Disponível em URL: http://www.scielo.br/rcbc

Endereço para correspondência:

Nelson Alfredo Smith

E-mail: n-smith@uol.com.br 